\title{
A study of the nutritional status and dietary intake of lactating women in Umuahia, Nigeria
}

\section{Ukegbu Patricia Ogechi}

Department of Human Nutrition and Dietetics, Michael Okpara University of Agriculture, Umudike, Abia State, Nigeria

Email address:

ukegbu.patricia@mouau.edu.ng

To cite this article:

Ukegbu Patricia Ogechi. A Study of the Nutritional Status and Dietary Intake of Lactating Women in Umuahia, Nigeria. American Journal of Health Research. Vol. 2, No. 1, 2014, pp. 20-26. doi: 10.11648/j.ajhr.20140201.14

\begin{abstract}
Background: The lactation period is a major source of concern in developing countries because of its positive impact on the health and nutrition of children. Adequate nutrition for the mothers is therefore important for their good health as well as for that of their offspring. Aim: The aim of this study was to assess nutritional status of lactating women in Umuahia, Nigeria. Materials and methods: This cross sectional study was conducted on 240 randomly selected women attending post natal clinics with their infants (0-6 months) in four health facilitates in Umuahia North Local Government Area (LGA) of Abia State, Nigeria. A structured, validated and pre-tested questionnaire was used to obtain information on socioeconomic characteristics. Body Mass Index (BMI) was used to assess nutritional status by taking height and weight measurements using standard procedures. Dietary intake was assessed using 24 hour recall and a validated food frequency questionnaire. Mean nutrient intake was calculated and expressed as percentages of FAO/WHO recommended values. Data was analyzed using descriptive statistics and Pearson correlation coefficient was used to determine association between BMI and nutrient intake. Results: Majority of the women $(71.30 \%)$ were in the age range of 26-35yrs and had a total family monthly income $>\mathrm{N} 20,000(85 \%)$. The prevalence of overweight and obesity were 52.10 and $18.30 \%$, respectively. Cereals/cereal based dishes (1430) and leafy/non leafy vegetables (1079) were consumed more frequently while legumes were less frequently consumed on a daily basis. Energy $(2279.01 \pm 446.79 \mathrm{kcal})$, protein $(50.02 \pm 12.23 \mathrm{~g})$, calcium $(339.21 \pm 186.35 \mathrm{mg})$ and vitamin A $(698.52 \pm 615.50 \mu \mathrm{gRE})$ intake were lower than recommendations. No significant correlation was found between BMI and energy intake $(\mathrm{p}=0.793)$. Conclusion: Intake of some essential nutrients was lower than recommendations. Intervention programs such as nutrition education and dietary diversity should be emphasized during antenatal and lactation period to improve better health and nutrition outcomes.
\end{abstract}

Keywords: Food Consumption, Lactating Women, Nutrient Intake, Nutritional Status

\section{Introduction}

The lactation period is a major source of concern in developing countries because of its positive impact on the health and nutrition of infants. Lactating women from developing countries are considered nutritionally vulnerable groups because this period places a high nutritional demand on the mother. Inadequate maternal diet during this period will lead to poor secretion of nutrients in breast milk and this can have long term impact on the child's health. ${ }^{[1-3]}$

It is reported that a lactating woman should produce about 700 to $800 \mathrm{ml}$ of milk per day and this requires an extra energy need of about 500 calories per day. ${ }^{[4]}$ Women who are severely malnourished have reduced lactation performance ${ }^{[5]}$, thus, the quantity of milk produced depends a lot on the mother's diet. The diet consumed by the mother will not only fulfill her own nutritional needs but will also enable her to produce enough milk for her infant. ${ }^{[4,6]}$

Nutritional status is an indication of the overall well being of a population. ${ }^{[4,6]}$ It has been reported that lactation has different effects on maternal nutritional status depending on its duration, intensity, as well as cultural diversity. ${ }^{[8]}$ In a cross sectional study ${ }^{[9]}$, it was reported that breastfeeding when practiced either exclusively or otherwise had no significant negative effect on the nutritional status of the mothers. Likewise, a longitudinal study ${ }^{[10]}$ observed that irrespective of breastfeeding pattern, lactation also had no profound effect on maternal body composition. However, the high energy cost of lactation as well as the nutritional and health risk it could pose for the woman emphasizes the need for continuous monitoring of their nutritional status and dietary intake in poor resource countries. A study carried out 
in the South western part of the country observed poor dietary intakes among lactating women studied. ${ }^{[1]}$

Information regarding the nutritional status and dietary intake of lactating mothers in the study area is scarce. The objective of this study was therefore to provide information about the nutritional status of lactating women as well as proffer solutions that are aimed at improving maternal nutrition in the study area.

\section{Materials and Methods}

\subsection{Study Area}

The study was conducted in Umuahia North Local Government Area (LGA) of Abia State, Nigeria. Umuahia city is an urban area and capital of the state with a landmass of 14,460 square kilometers. The population of the LGA according to the 2006 census was 239,020. ${ }^{[12]}$ All state ministries, departments and the secretariat are centrally located in this Local Government Area. The inhabitants of the town are involved in business, civil service, trading as well as artisan work. In the LGA, there is one tertiary health institution i.e. Federal Medical Centre and 14 Primary Health Care centers (PHC). All the government health institutions in the LGA are designated as "Baby Friendly Hospitals". These health institutions operate antenatal, postnatal and child welfare clinics which carter for pregnant/lactating women and their babies residing within and outside the local government.

\subsection{Study Design}

This was a cross sectional study carried out between April to July, 2011.

\subsection{Sampling Procedure}

The subjects included lactating women with their infants who were attending immunization clinics every Wednesday at four randomly selected health centers (World Bank Health Centers, Health Office Adelabu, Ojike Infant Welfare Office and Federal Medical Centre, Umuahia) from 15 listed health facilities. The subjects were recruited by the researcher and trained research assistants consecutively for 4 weeks in each of the health facilities by simple random sampling (balloting) technique. On each clinic day, a list of mother-infant pairs who were registered for immunization was used as the sampling frame and they were assigned identification (ID) numbers. The identification numbers were listed in separate pieces of papers and placed into a bag. The papers were shuffled (randomized) after which ballots were drawn from the bag without replacement. This exercise was repeated on every clinic day until the required sample size was attained.

\subsection{Inclusion Criteria}

The criteria for defining lactating women were if they were apparently healthy and reported breast feeding at least 3 times a day. ${ }^{[13]}$ The purpose of the study was explained to the women and their informed consent was obtained prior to commencement of the study. The study was approved by the ethics committee of the Federal Medical Centre (FMC), Umuahia.

\subsection{Sample Size Determination}

Sample size of 240 was calculated using the formula $n$ $=Z^{2} \times p(100-p) / X^{2}{ }^{[14]}$, where $Z$ represents the standard normal deviate set at 1.96 which corresponds to $95 \%$ confidence level, $\mathrm{x}$ is $5 \%$ margin of error and $\mathrm{p}$ is $17 \%$ estimated prevalence of exclusive breastfeeding. ${ }^{[15]}$ The calculated sample size was 216 . In order to make up for attrition, an anticipated 90\% (0.9) response rate was used. The estimated sample size was thus calculated by dividing the originally calculated sample size by the anticipated response rate as $216 / 0.9=240$. A total number of 240 subjects were used for data collection.

\subsection{Data Collection}

Eight research assistants made up of nursing and nutrition students were recruited and trained for data collection. They were trained for three days by the researcher on administration and interpretation of questionnaire in the local dialect, anthropometric measurements and use of food models and household measuring instruments to estimate the quantity of foods consumed by mothers.

\subsubsection{Socio-Demographic Characteristics}

A structured questionnaire was used to obtain information on socio-demographic characteristics of the subjects such as age, occupation, education, income, number of children, household size and marital status. This questionnaire was validated by six lecturers in the Department of Human Nutrition and Dietetics and four nurses in the selected health facilities in order to modify the instrument. Their suggestions and corrections were incorporated into the final draft of the questionnaire. A pre-test was carried out using mothers attending immunization clinics at General Hospital Amachara in Umuahia South LGA. These group of mothers were not used in the final study.

\subsubsection{Anthropometric Measurements}

Weight measurement was taken using a portable bathroom scale (Hanson model). The subjects were asked to remove any clothing which might change body weight and remove their shoes while standing erect on the weighing scale. Readings were taken to the nearest $0.1 \mathrm{~kg}$. Height was measured using a portable heightometer with a movable head piece while subjects stood erect on bare foot. Measurement was taken to the nearest $0.1 \mathrm{~cm}$. BMI was calculated as weight $(\mathrm{kg})$ divided by height $\left(\mathrm{m}^{2}\right)$ for each subject. All measurements were taken and recorded in duplicates using standard procedures. ${ }^{[16]}$

\subsubsection{Dietary Intake Assessment}

Dietary intake was assessed using a previously validated 24 hour recall and qualitative food frequency questionnaire 
(FFQ).${ }^{[17]}$ For the 24 hour recall, the subjects were asked to recall all foods and beverages consumed during the past 24 hours. The use of common household utensils and models of portion sizes were used to aid the women estimate the amount of food they consumed and these were converted to grams using household measures. For commercially prepared foods such as biscuits, an equivalent was bought and weighed to minimize the amount of weighing the women had to do. In the case of packaged foods, information was obtained from the nutrition facts on the package. For foods not found in the Food Composition Tables (FCT) ${ }^{[18]}$, duplicate samples of the foods and meals were collected from the homes of some of the subjects, placed in plastic box and transported in an insulated container with ice to the laboratory for chemical analysis. The average nutrient intake was calculated for each individual using Food composition table. ${ }^{[18]}$ The food frequency questionnaire was used to ascertain the frequency of consumption of certain foods in the list on daily, weekly or monthly basis.

Proximate composition of foods not found in the food composition table was determined using standard methods. Fat was determined using soxhlet extraction method, protein was by microkjeldahl method, while carbohydrate was determined by difference. ${ }^{[13]}$ Energy values were calculated using Atwater factors of 4,4 and $9 \mathrm{kcal}$ for protein, carbohydrates and fat, respectively. Vitamin $\mathrm{C}$ was determined by titration method ${ }^{[19]}$ and vitamin A was by methods of Reddy and Sistrunk ${ }^{[20]}$. Iron, zinc and calcium were determined after wet digestion with nitric acid and perchloric acid using the Atomic absorption spectrophotometer. ${ }^{[21]}$

\subsection{Data/Statistical Analysis}

Statistical analysis was carried out using SPSS for windows version 15.0. Results were expressed as means and standard deviations, frequencies and percentages, while Pearson correlation was used to determine relationship between BMI and nutrient intake. Average nutrient intakes were compared to $\mathrm{FAO} / \mathrm{WHO}{ }^{[22,23]}$ reference values for lactating women and the percentages of recommended intake met by the mothers was estimated. A p-value of less than 0.05 was regarded as statistically significant.

\section{Results}

Table 1 depicts the socio-demographic characteristics of lactating women. Majority of mothers $(71.30 \%)$ were in the age range of 26-35 years. Most of them (42.90\% and $49.20 \%)$ had either secondary or tertiary education. About one third $(37.50 \%)$ were civil servants, few $(15 \%)$ had total family monthly income less than N20,000, more than two-thirds (73.70\%) had between 1-3 children while a high percentage of the women were married $(97.5 \%)$.

Anthropometric measurements showed that the women had a mean height, weight and BMI of $1.59 \pm 0.63 \mathrm{~cm}$, $68.42 \pm 10.37 \mathrm{~kg}$ and $27.31 \pm 3.4 \mathrm{~kg} / \mathrm{m}^{2}$, respectively. About half $(52.10 \%)$ of the women are overweight, while $18.30 \%$ are obese [Table 2].

Table 1. Socio-demographic characteristics of the lactating women

\begin{tabular}{|c|c|c|}
\hline Parameters & Frequency & Percentage (\%) \\
\hline \multicolumn{3}{|l|}{ Age } \\
\hline $16-25$ & 51 & 21.3 \\
\hline $26-35$ & 171 & 71.3 \\
\hline $36-45$ & 18 & 7.5 \\
\hline Total & 240 & 100 \\
\hline \multicolumn{3}{|c|}{ Mother's educational qualification } \\
\hline Primary education & 19 & 7.9 \\
\hline Secondary education & 103 & 42.9 \\
\hline Tertiary education & 118 & 49.2 \\
\hline Total & 240 & 100 \\
\hline \multicolumn{3}{|l|}{ Mother's occupation } \\
\hline Civil servant & 90 & 37.5 \\
\hline Full time housewife & 52 & 21.7 \\
\hline Student & 37 & 15.4 \\
\hline Trader & 35 & 14.6 \\
\hline Artisan & 15 & 6.3 \\
\hline Farmer & 11 & 4.6 \\
\hline Total & 240 & 100 \\
\hline \multicolumn{3}{|l|}{ Total family income } \\
\hline$<\mathrm{N} 20,000$ & 36 & 15.0 \\
\hline $\mathrm{N} 21,000-50,000$ & 76 & 31.7 \\
\hline N51,000-100,000 & 79 & 32.9 \\
\hline$>100,000$ & 49 & 20.4 \\
\hline Total & 240 & 100 \\
\hline \multicolumn{3}{|l|}{ Parity } \\
\hline $1-3$ & 177 & 73.7 \\
\hline $4-6$ & 56 & 23.3 \\
\hline$\geq 7$ & 7 & 3.0 \\
\hline Total & 240 & 100 \\
\hline \multicolumn{3}{|l|}{ Household size } \\
\hline $1-3$ & 65 & 27.1 \\
\hline $4-6$ & 149 & 53.8 \\
\hline$\geq 7$ & 46 & 19.1 \\
\hline Total & 213 & 100 \\
\hline \multicolumn{3}{|l|}{ Marital status } \\
\hline Married & 234 & 97.5 \\
\hline Single & 4 & 1.7 \\
\hline Separated/divorced & 2 & 0.8 \\
\hline Total & 213 & 100 \\
\hline
\end{tabular}

Table 2. Anthropometric characteristics of the lactating women

\begin{tabular}{lc}
\hline Parameter & Mean $( \pm$ SD) \\
\hline Height $(\mathrm{cm})$ & $1.59 \pm 0.63$ \\
Weight $(\mathrm{kg})$ & $68.42 \pm 10 . .37$ \\
BMI $\left(\mathrm{kg} / \mathrm{m}^{2}\right)$ & $27.31 \pm 3.4$ \\
BMI classification & Freq (\%) \\
Underweight $\left(<18.49 \mathrm{~kg} / \mathrm{m}^{2}\right)$ & $3(1.25)$ \\
Normal $\left(18.50-24.99 \mathrm{~kg} / \mathrm{m}^{2}\right)$ & $68(28.33)$ \\
Overweight $\left(25.00-29.99 \mathrm{~kg} / \mathrm{m}^{2}\right)$ & $125(52.10)$ \\
Obese $\left(>30.00 \mathrm{~kg} / \mathrm{m}^{2}\right)$ & $44(18.30)$ \\
\hline
\end{tabular}

$\mathrm{SD}=$ Standard deviation

Analysis of energy and selected nutrient intake of the 
women as well as percentage of the requirements met as shown in Table 3 revealed that the women exceeded the requirements for carbohydrate, iron, zinc and vitamin $\mathrm{C}$. Although, protein, carbohydrate and vitamin A requirement were above average, calcium was however, well below requirement. Fat was within the range of $15-30 \%$ recommended [Table 3].

As illustrated in Table 4, cereals/cereal based dishes (1430) and leafy/non-leafy vegetables (1079) were more commonly consumed, while legumes (374) were less frequently consumed daily.

Table 3. Average energy and selected nutrient intake of lactating women

\begin{tabular}{|c|c|c|c|}
\hline Nutrients & Mean intake & RNI* & $\%$ of RNI met \\
\hline Energy (kcal) & $2279.01 \pm 446.79$ & 2600 & 87.65 \\
\hline Protein $(\mathrm{g})$ & $50.02 \pm 12.23$ & 64 & 78.16 \\
\hline Carbohydrate (g) & $408.69 \pm 94.00$ & $180-230$ & 177.69 \\
\hline Fat (g) & $45.52 \pm 13.50$ & $15-30 \%$ of energy intake & - \\
\hline Calcium (mg) & $339.21 \pm 186.35$ & 1000 & 33.92 \\
\hline Iron (mg) & $33.48 \pm 19.47$ & $10-30$ & 111.60 \\
\hline Zinc (mg) & $10.03 \pm 8.01$ & 9.5 & 105.58 \\
\hline Vitamin A $(\mu \mathrm{gRE})$ & $698.52 \pm 615.60$ & 850 & 82.18 \\
\hline Vitamin C (mg) & $76.83 \pm 52.00$ & 70 & 109.75 \\
\hline
\end{tabular}

Table 4. Frequency of food consumption by the lactating women

\begin{tabular}{lccccc}
\hline Food group & Daily & Weekly & Monthly & Rarely & Total \\
\hline Starchy roots and tubers & $452(34.50)$ & $285(21.76)$ & $227(17.33)$ & $340(26.41)$ & $1304(100)$ \\
Cereals & $1430(67.58)$ & $224(10.89)$ & $249(11.77)$ & $213(10.07)$ & $2116(100)$ \\
Legumes & $374(21.40)$ & $240(13.71)$ & $387(22.10)$ & $750(42.83)$ & $1751(100)$ \\
Meat \& meat alternate group & $570(34.34)$ & $624(37.60)$ & $233(14.03)$ & $233(14.03)$ & $1660(100)$ \\
Leafy and non leafy vegetables & $1079(43.63)$ & $320(12.94)$ & $646(26.12)$ & $428(17.31)$ & $2473(100)$ \\
Fruits & $584(33.62)$ & $251(14.45)$ & $377(21.70)$ & $525(30.22)$ & $1737(100)$ \\
Fats \& oils & $426(100)$ & - & & - & $426(100)$ \\
\hline
\end{tabular}

Figures in parentheses are percentages

Correlation analysis in Table 5 showed that there was no relationship between energy intake and BMI $(p=0.793)$. However, a significant association was observed between fat intake and weight $(\mathrm{p}=0.033)$ as well as fat intake and BMI $(\mathrm{p}=0.042)$

Table 5. Correlation between energy intake and anthropometry

\begin{tabular}{lllll}
\hline Parameters & Energy & Protein & Fat & Carbohydrate \\
\hline Height & $0.073(0.559)$ & $0.013(0.915)$ & $0.105(0.400)$ & $0.020(0.875)$ \\
Weight & $0.100(0.423)$ & $0.091(0.465)$ & $0.263(0.033)^{*}$ & $0.001(0.996)$ \\
BMI & $0.330(0.793)$ & $0.107(0.395)$ & $0.251(0.042)^{*}$ & $0.067(0.594)$ \\
\hline
\end{tabular}

$*=p<0.05$, Figures in parentheses are level of significance

\section{Discussion}

This study provides information on the nutritional status and dietary intake of lactating women in Umuahia, Nigeria. The result showed that the age range (26-35 years) of majority of the lactating women is consistent with findings of an earlier study of similar population in Nigeria. ${ }^{[11,24-25]}$ According to Umeora and Egwuatu ${ }^{[26]}$, this age range reflects the reproductive age group.

The data obtained also indicate that majority of the lactating women had high literacy level, income and occupation. In developing countries, it has been reported that the income of a household is an important determinant of its access to food which in turn is a major determinant of child and maternal nutrition and wellbeing. [27,28] Epidemiological studies have reported on the relationship between diet and poverty; and the report established that the purchasing power of a family dictates the level of household food security and types of diets that are ultimately consumed by household members. ${ }^{[29,30]}$ Likewise, the mean BMI $\left(27.31 \pm 3.4 \mathrm{~kg} / \mathrm{m}^{2}\right)$ obtained in this study corresponds to overweight category on the BMI scale. Most of the women were overweight and obese, respectively. In African culture, overweight and obesity are socially acceptable as a sign of wealth and good living. ${ }^{[31]}$ In Nigeria, among the 'igbo' tribe where this study was carried out, it was reported that weight gain during lactation period is considered normal. ${ }^{[17]}$ After delivery, mothers are expected to be confined at home and adequately cared for by their husbands and relatives. This creates an opportunity for them to nurse their baby, feed well and reduce their activity level. ${ }^{[10]}$ Similarly, other authors 
have reported that lactating women they studied were overweight ${ }^{[32,33]}$ while some others have shown that they were either normal or obese. ${ }^{[9,34,35]}$

Data on food consumption showed that the women consumed a variety of foods from cereals, roots/tubers, legumes and fruits/vegetables. However, their diets were mainly starch based and low in fruits and vegetables. Their mean energy intake was slightly $(320 \mathrm{kcal})$ lower than recommendation. This is consistent with findings from other developing countries among lactating women ${ }^{[36,37]}$. It was however lower when compared to reports from developed countries. ${ }^{[35,38]}$ Despite the fact that the mean energy intake in this study was lower than standards, more than $70 \%$ had high BMI. The high BMI could be due to the weight gained during pregnancy. Again, the BMI recommendation for normal adults was used in classifying the lactating women since there is no recommended standard for them. This may also have placed majority of the women in the overweight and obese categories as noted by WHO ${ }^{[39]}$ The result of the present study corroborates that carried out among a group of Brazilian lactating women which showed a high prevalence of overweight despite a lower energy intake below the recommended level. ${ }^{[40]}$ No significant association was observed between energy intake and nutritional status (BMI) in this study ( $p=0.793)$. This is however contrary to a study ${ }^{[9]}$ which showed a weak but positive association between both variables. The recommended level of energy distribution is $55-65 \%$ for carbohydrate, $12-16 \%$ for protein and $15-30 \%$ for fat. ${ }^{[16]}$ It was however observed that the distribution of total calories from carbohydrate $(72.8 \%)$ and fat $(18.3 \%)$ were within the recommended level of energy distribution, while protein $(8.9 \%)$ was less than recommendation.

The mean carbohydrate intake was $408.69 \mathrm{~g}$ and the women exceeded the recommendation by well over $70 \%$. Tubers and cereals were observed to be consumed on a daily basis from their food consumption data. These foods represent the major staples in this part of the country. It was therefore not surprising to find that the lactating women had a high carbohydrate intake. Dietary protein is required by lactating women for the synthesis of protein in breast milk, maintenance and repair of cells. ${ }^{[41]}$ Based on results obtained from this study, the protein intake was $21.84 \%$ below recommendation. Their sources of protein were mainly plant based (cereals and legumes). From their food consumption data, animal sources of protein were consumed more on a weekly basis $(37.60 \%)$ than on a daily basis $(34.34 \%)$. The frequency of consumption of beans and other legumes was low as majority of the mothers rarely consumed them. Other bean and legume products were consumed than the legumes themselves. The lactating women met $15-20 \%$ of their fat requirement. Fat was mainly provided by red palm oil and vegetable oil used in frying and making soups/sauces. These oils were used on a daily basis by the women and this is typical in south eastern part of the country.

Plant based foods have been noted to contain micro nutrients with low bioavailability. ${ }^{[42]}$ This is due to the presence of some nutrients which may limit absorption of certain micro nutrients. ${ }^{[41]}$ Therefore, continued dependence of the women mainly on starchy staples can place them at risk of micronutrient deficiencies (hidden hunger). Intake of some of the selected micronutrients was below recommendation. Insufficient calcium intake (below average) was evident in the lactating women. Studies ${ }^{[43,44]}$ have reported that intakes of $200-500 \mathrm{mg}$ calcium per day is typical in African and Asian countries where the consumption of animal milk is low, while average calcium consumption in Northern Europe, Northern America and Australia is in excess of $1000 \mathrm{mg} \mid \mathrm{d}$. In this study, milk was not consumed alone but was consumed in small quantities either as part of beverages mainly tea or added to maize gruel or custard. Insufficient calcium intake has also been reported among lactating women in Italy and Spain. ${ }^{[45,46]}$

Surprisingly, the iron and zinc intake of the lactating women were high. Iron and zinc intake observed could only be apparent since bioavailability was not taken into consideration. The intake of these nutrients was mainly from plant sources which have been shown to contain low bioavailability. Absorption of iron has been noted to be enhanced when consumed with vitamin $\mathrm{C}$ rich foods in the diet. ${ }^{[45]}$ The vitamin $\mathrm{C}$ intake of the women was mainly from citrus fruits. The adequate vitamin $\mathrm{C}$ intake could probably have enhanced the iron in the diet of the women.

Vitamin A in the form of carotenoids exists in Nigeria dishes. Sanusi and Adebiyi ${ }^{[48]}$ reported that the diets of populations in tropical countries rarely contain large amounts of milk, eggs and liver which are rich sources of preformed vitamin A. This thus makes people depend on carotenoids particularly from leafy vegetables and palm oil as sources of vitamin A. The lactating women in this study met their vitamin A requirement by $82.18 \%$. The main sources of vitamin A for the women were red palm oil (added to soups, sauces, porridges and for frying), dark and colored leafy vegetables as well as fruits. Similar findings have been reported among lactating and pregnant women in Ghanaian communities. [47,49] The frequency of food consumption revealed that red palm oil and vegetable oil was consumed on a daily basis. Vegetable oil is fortified with vitamin A, while red palm oil is known to contain high amounts of beta carotene. The lactating women were also found to consume dark and colored vegetables and fruits, which are good sources of provitamin A.

\section{Conclusion}

Majority of the lactating women were either overweight or obese. Intake of some essential macro and micro nutrients was lower than recommendation in this study. Dietary intake consisted mainly of plant based foods (cereals, roots and tubers) with low bioavailability and which may not be adequate to support increased nutrient requirements during the lactation period. Intervention programs such as nutrition education, food supplementation and dietary diversity should be emphasized during antenatal and lactation period to improve better health and nutrition outcomes. Due to the 
cross sectional nature of the study, it is suggested that longitudinal assessment be carried out in the study area in order to ascertain nutritional status of lactating women over a longer period of time.

\section{Limitations of the study}

Caution should be observed in the interpretation of the results as this may have been affected by the cross sectional nature of the study. Again, interpretation of the BMI should be done with caution as there is no specific classification for lactating women. The values used are for normal adult women.

\section{Acknowledgements}

The research was supported by a scholarship from Federal Government of Nigeria (FGN) in collaboration with Federal Scholarship Board, Abuja (REF: FSBA/FGSS/PG/09/029).

\section{References}

[1] Picciano MF. Nutrient composition of Human milk, Pediatric Clinics of North America. 2001; 48(1):53-67.

[2] Marcos A, Nova E, Montero A. Changes in the immune system are conditioned by nutrition. Euro J Clin Nutr 2003; 57:S66-S69.

[3] Jones KDJ, Berkley JA, Warner JO. Perinatal nutrition and immunity to infection. Paedatric Allergy and Immunology 2010; 21:564-576.

[4] Sylvia B, Mary Dowd S. The Nursing Mother's Diet. The art of successful breastfeeding: A Mother's Guide ; 2002.

[5] Allen LH. B vitamins in Breast Milk: Relative importance of maternal status and intake and effects on infant status and function. Adv Nutr 2012; 3:362

[6] Demissie T, Mekonen Y, Haider J. Agro-ecological comparison levels and correlate of nutritional status of women. Ethiop J Health Dev 2003; 17:189-196.

[7] Wardlaw, G.N and Kessel M. Perspectives in Nutrition. $2^{\text {nd }}$ edition. MaGraw Hill Publishers, USA; 2002.

[8] Rasmussen KM. and McGuire KM. Effects of breastfeeding on maternal health and well-being. Fd Nutr Bull 1996; 17:4.

[9] Sanusi RA, Falana OA. The nutritional status of mothers practicing breastfeeding. Afr J Biomed Res 2009; 12;2.

[10] Ukegbu, PO, Uwaegbute, AC. Body composition changes among lactating mothers in Abia State, Nigeria. American Journal of Food and Nutrition. Am J Fd Nutr 2012; 2(1): 21-25.

[11] Ijarotimi OS. Assessing exclusive breastfeeding practices, dietary intakes and body mass index (BMI) of nursing mothers in Ekiti State of Nigeria. Nutrition Research and Practice 2010;4(3):222-228

[12] NPC. National Population Commission and ICF Macro, Abuja, Nigeria 2008
[13] Dufour DL, Reina JC, Spurr GB. Energy intake and expenditure of free living lactating Columbian women in an urban setting. Euro J Clin Nutr 2002; 56:205-36.

[14] Araoye MO. Research methodology with statistics for health and social sciences. Nathadex publishers, Nigeria; 2003; $117-119$

[15] NDHS. Nigeria Demographic and Health Survey. Federal Office of Statistics Lagos, Nigeria. ORC Macro,Calverton, Maryland, USA; 2003.

[16] WHO. Physical status: The use and interpretation of anthropometry. Who Technical Report Series 1995; 854:375-409.

[17] Ukegbu PO. Effect of maternal nutrition and body composition on lactation performance and breast milk composition. $\mathrm{PhD}$ Thesis, Michael Okpara University of Agriculture, Umudike Abia State Nigeria; 2012.

[18] Oguntona EB, Akinyele IO. Nutrient composition of commonly eaten foods in Nigeria: raw, processed and prepared. Food Basket Foundation Publication Series, Ibadan; 1998.

[19] Kirk RS, Sawyerr R. Pearson's composition and analysis of foods. $9^{\text {th }}$ Ed. Longmans Scientific and Technical, England; $1991 ; 223-46$.

[20] Reddy NN, Sistrunk WA. Effect of cultivar, size, storage and cooking methods on carbohydrate and some nutrients of sweet potato. J Fd Sci 1980; 45(3):682-4.

[21] AOAC. Official Methods of Analysis. Association of Official Analytical Chemist, Washington DC; 2000; 547-67.

[22] FAO/WHO. Human and mineral requirements. Report of a Joint FAO/WHO Expert Consultation. FAO, Rome; 2002; 251-70.

[23] FAO/WHO. Human Energy Requirements. Report of a Joint FAO/WHO/UNU Expert Consultation. Food and Nutrition Technical Report Series, FAO, Rome; 2004.

[24] Ukegbu PO, Uwaegbute AC, Ijeh II Anyika JU. Influence of maternal anthropometric measurements and dietary intake on lactation performance in Umuahia urban area of Abia state Nigeria. Nig J Nutr Sci 2012; 33(2):31-9.

[25] Sanusi, R. A and Falana, O. A. The Nutritional Status of Mothers Practicing Breast Feeding In Ibadan, Nigeria. Afr. J. Biomed. Res 2009; 12(2):107-112.

[26] Umeora O, Egwuatu V. Age at menache and menstrual pattern of Igbo women of South East Nigeria. African Reproductive Health 2008; 12(1):90-5.

[27] Lisa CS, Lawrence H. Explaining child malnutrition in developing countries: A cross-country analysis. Research Report. 2000; 111:4.

[28] Müller O, Krawinkel M. Malnutrition and health in developing countries. CMAJ 2005; 173:279-86

[29] Kinra S, Nelder RP, Lewendon GJ. 'Deprivation and childhood obesity: a cross sectional study of 20,973 children in Plymouth, United Kingdom'. J Epidemiol Community Health 2000; 54:456-60.

[30] Coakley A. Healthy eating: food and diet in low income households. Administration. 2001; 49: 87-103. 
[31] Desalu OO, Salami Ak, Oluboye PO, Olarinoye JK (2008). Prevalence and socio-demographic determinants of obesity among adults in an urban Nigerian population. Sahel Med J 2008; 11(2):61-64.

[32] Mahdavi R, Nikniaz L, Arefhosseini S. Energy, fluids intake and beverages consumption pattern among lactating women in tabriz, Iran. Pakistan J Nutr 2009; 8(1):69-73.

[33] Kulkarni B, Shatrugna V, Nagalla B, Rani U. Regional body composition changes during lactation in Indian women from the low-income group and their relationship to the growth of their infants. J Am Coll Nutr 2011; 30(1):57-62.

[34] Cunha J, Macedo da Costa T, Ito MK. Influences of maternal dietary intake and suckling on breast milk lipid and fatty acid composition in low-income women from Brasilia, Brazil. Early Hum Dev 2005; 81(3): 303-11.

[35] Caire-Juvera G, Ortega M, Casanueva E, Bolanos A, de la Barca A. Food components and dietary patterns of two different groups of Mexican lactating women. J Am Coll Nutr 2007; 26(2):156-62.

[36] Alam, DS, Van-Raaij JMA, Hautvast JGAJ, Yunies M, Fuchs GJ. Energy stress during pregnancy and lactation: consequences for maternal nutrition in rural Bangladesh. Euro J Clin Nutr 2003; 57:151-56.

[37] Ayatollahi SMT, Moghaddam AR. A statistical survey on Nutritional status of lactating women. MJIRC 2004; 7(1):15-17.

[38] McLachian, S.K., Christine, D.T., Elaine, L.F. and Janne, G.M. Dietary and biochemical selenium status of urban 6-24 month old south Island New Zealand children and their postpartum mothers. 2004; J Nutr 134:3290-3295.

[39] WHO. Obesity: preventing and managing the global epidemic. Report of a WHO Consultation. Geneva: WHO Technical Report Series, 894; 2000

[40] Tavares MP, Devincenzi MU, Sachs A, Freitas de Vilhena Abrão AC. Nutritional status and diet quality of nursing mothers on exclusive breastfeeding. Acta Paul Enferm. 2013; 26(3):294-8.
[41] Chen H, Wang P, Ha Y, Ma J, Troy FA, Wang BE. Evaluation of dietary intake of lactating women in China and its potential impact on the health of mothers and infants. BMC Women's Health 2012; 12:18.

[42] Neumann C, Bwibo N, Murphy S, Sigman M, Whaley S, Allen L, Guthrie D, Weiss R, Demment M. Animal source foods improve dietary quality, micronutrient status, growth and cognitive function of Kenyan school children: Background, study design and baseline findings. Journal of Nutrition 2003; 133:3941S-49S.

[43] Prentice A, Dibba B, Jarjou, LMA, Laskey, MA. Paul AA. Is breast milk calcium concentration influenced by calcium intake during pregnancy? The Lancet 1994; 344.

[44] Zapata CV, Donangdo CM, Woodhouse LR, Abrams SA, Spencer EM, King JC. Calcium homeostasis during pregnancy and lactation in Brazilian women with low calcium intake: a longitudinal study. Am J Clin Nutr 2004; 417-439.

[45] Savino F, Bermond S, Bonfante G, Gallo E, Oggero R. Food intakes in breast-feeding mothers. Minerva Pediatrica 2001; 53:177-82.

[46] Sanchez CL, Rodriguez AB, Sanchez J, Gonzales R, Rivero $\mathrm{M}$, Barriga C, Cubero J. Calcium intake nutritional status in breastfeeding women. Arch Latinoam Nutrition 2008; 58:371-76.

[47] Kobati GY, Lartey A, Marquis GS, Colecraft EK, Butler LM. Dietary intakes and body mass indices of non-pregnant, non-lactating (NPNL) women from the coastal and Guinea Savannah zones of Ghana. Afr J Fd, Agric Nutr Dev 2005; 12(1):5843-61.

[48] Sanusi RA, Adebiyi AE. Proximate and mineral composition of commonly consumed foods in Nigeria. Nig J Nutr Sci 2009; 2:54-63.

[49] Nti CA, Larweh PM, Gyemfua-Yeboah Y. Food consumption patterns, dietary quality and health status of expectant mothers: case studies in suburban and rural communities in Ghana. Int J Cons Stud 2002; 26:7-14. 